Received: 2017.08.19

Accepted: 2017.09.11

Published: 2017.10.03

\title{
Role of Paeonol in an Astrocyte Model of Parkinson's Disease
}

Authors' Contribution: Study Design A Data Collection B Statistical Analysis C Data Interpretation D Manuscript Preparation E Literature Search F Funds Collection G

Corresponding Author: Source of support:

Background:

Material/Methods:

Results:

Conclusions:

MeSH Keywords:

Full-text PDF:
Maosheng Ye, e-mail: yemaoshenghzrch@126.com Departmental sources
1 Department of Geriatrics, Hangzhou Red Cross Hospital, Hangzhou, Zhejiang, P.R. China

2 Department of Geriatrics, The Second Xiangya Hospital, Central South University, Changsha, Hunan, P.R. China

Parkinson's disease (PD) is characterized by a progressive degeneration of dopaminergic (DA) neurons in the substantia nigra pars compacta (SNc). Inflammation and neural degeneration are implicated in the pathogenesis of PD. Paeonol has been verified to attenuate inflammation.

1-methyl-4-phenylpyridnium ion (MPP+, $100 \mu \mathrm{M})$ was used to induce the cell model of PD in primary cultured astrocytes. Astrocyte cell viability and apoptosis were determined by 3-(4, 5-dimethyl-2-thiazolyl)-2, 5-diphenyl-2-H-tetrazolium bromide (MTT) assay and flow cytometry (FCM), respectively. Protein levels of cyclooxygenase-2 (COX-2) and inducible nitric oxide synthases (iNOS) in culture medium were tested by enzyme-linked immunosorbent (ELISA) assay. Protein levels of casapse-1, COX2, iNOS, B-cell lymphoma 2 (Bcl-2)-associated $X$ protein (Bax), Bcl-2, and phosphorylated Jun N-terminal kinase ( $\mathrm{p}$-JNK)/phosphorylated extracellular signalregulated kinase (p-ERK)/p-P38 were examined by Western blot.

Pretreatment with paeonol remarkably rescued $\mathrm{MPP}+$-induced cell viability reduction, up-regulation of cell apoptosis, caspase- 1 activity, COX-2, iNOS, and Bax/Bcl-2 ratio in primary astrocytes. Furthermore, paeonol repressed MPP+ -induced elevation of $\mathrm{p}$-JNK/p-ERK in primary cultured astrocytes.

The present study found that paeonol protected cells from apoptosis by repressing the activation of the JNK/ERK related signalling pathway induced by MPP+ in astrocytes. We propose that paeonol is a neuroprotective agent for the treatment of PD patients, with great promise in the future.

Astrocytes • Paeonia • Parkinson Disease

https://www.medscimonit.com/abstract/index/idArt/906716

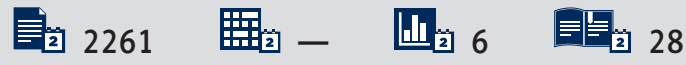




\section{Background}

Parkinson's disease (PD) is named after James Parkinson, an English doctor who, in 1817, first reported the disease and gave a description in An Essay on the Shaking Palsy [1,2]. In recent years, there are 8-18 new cases of PD/year/100 000 persons worldwide [3]. Numerous environmental factors, including head injury, living in the country/farming, and pesticide exposure, are positively correlated with an increased risk of PD $[4,5]$.

In the central nervous system, PD is a type of chronic neurodegenerative disorder which affects the motor system [6], termed "parkinsonism" or "parkinsonian syndrome" [7,8]. PD can be classified into 4 kinds of motor symptoms - tremor, slowness of movement, rigidity, and postural instability [9] - which are the consequences of dopaminergic cell death in the substantia nigra [10], but the cause of this cell death is poorly understood [8].

To date, there is no therapeutic approach to cure PD (6). In the early 1980s, 1-methyl-4-phenyl-1,2,3,6-tetrahydropyridine (MPTP) was discovered to have the ability to cause parkinsonian syndrome in non-human primates and in humans [11]. Thereafter, MPTP and its metabolite, MPP+, were widely used for PD research in animal models [12]. Moreover, the administration of MPTP was verified to evoke a sustained inflammation in the SN of monkeys $[13,14]$. In addition, low-reactive astrocytosis was found in the $\mathrm{SN}$, and was demonstrated to be responsible for the inflammation process in PD [15].

Paeonol, a phenolic compound from peonies (Paeonia suffruticosa) $[16,17]$, is used in some Traditional Chinese Medicine remedies [18]. Multiple biological effects of paeonol have been reported in animal models, such as improved rat behavior in a model of Alzheimer's disease [19], reduced microglia activation in ischemia-reperfusion-injured rats [20], and anti-inflammation [21]. However, whether paeonol palys a role in the astrocyte cell model of PD was unknown. The present study investigated the effects of paeonol in PD and explored a possible therapeutic approach for the treatment of PD.

\section{Material and Methods}

\section{Cell culture}

Briefly, astrocytes were extracted from neonatal mice. Cerebral cortices were isolated in medium containing DNase $(20 \mu \mathrm{g} / \mathrm{mL})$ and bovine serum albumin (BSA, $0.3 \%$ ). At $37^{\circ} \mathrm{C}$, tissues were digested in a solution of $0.25 \%$ trypsin/EDTA for half an hour. Thereafter, cells were filtered with a 70- $\mu$ m nylon filter, centrifugated, and resuspended in Dulbecco's modified Eagle's medium/F12 (DMEM/F12) supplemented with $10 \%$ fetal bovine serum (FBS) and $1 \%$ penicillin/streptomycin, transferred to flasks, and incubated in an incubator at $37^{\circ} \mathrm{C}$ with $5 \% \mathrm{CO}_{2}$. Flasks were shaken lightly to remove microglia cells and oligodendrocytes if the cultured astrocytes reached $80 \%$ confluence. Afterwards, the obtained pure astrocytes were washed with phosphate-buffered saline (PBS) 3 times for 10 min per time, and digested with $0.25 \%$ trypsin/EDTA. After taking away the medium, astrocytes were placed in new flasks and cultured in DMEM/F12 including 15\% FBS, L-glutamine, and $500 \mathrm{ng} / \mathrm{mL}$ insulin. Astrocytes were harvested after they reached $80 \%$ confluence for performing subsequent experiments.

We used $100 \mu \mathrm{M}$ MPP+ (Sigma, St. Louis, MO) to induce the cell model of PD. Astrocytes were first treated with different concentrations of paeonol $(0.75,1$, and $1.5 \mu \mathrm{mol} / \mathrm{L})$ (Tianzhen Pharmaceutical Company of Ningbo, Zhejiang, China), and $2 \mathrm{~h}$ later, the cells were treated with MPP+ and further cultured at an incubator for another $24 \mathrm{~h}$ for use in subsequent experiments.

\section{ELISA assay}

Protein levels of COX2 and iNOS in culture medium were tested by ELISA assay after exposure of astrocytes to $100 \mu \mathrm{M} \mathrm{MPP+}$ for $24 \mathrm{~h}$. We first sensitized 96-well plates by synthetic peptide, then placed them in an oven at $4^{\circ} \mathrm{C}$ overnight until dry, blocked them with $2 \%$ BSA for $2 \mathrm{~h}$, and treated them with samples for $1 \mathrm{~h}$ at $37^{\circ} \mathrm{C}$ after antigen sensitization. Biotinylatedlabeled human-IgG antibodies (Sigma, St. Louis, MO) were added to plates and incubated for $1 \mathrm{~h}$, followed by the addition of streptavidin-peroxidase and incubation for $30 \mathrm{~min}$ at $37^{\circ} \mathrm{C}$. After washing 3 times, substrate 3, 39, 5, 59-tetramethylbenzidine (TMB) was added to each well. Reactions were stopped by $\mathrm{H}_{2} \mathrm{SO}_{4}(2 \mathrm{~N})$. Optical density was read at $450 \mathrm{~nm}$ by use of an ELISA reader (BioRad, Hercules, CA).

\section{Western blot}

To test protein levels of p-ERK/p-JNK/p-P38 MAPK, Bax/Bcl-2, caspase-1, COX2, and iNOS in different groups, astrocyte lysates were homogenized by RIPA lysis buffer. Proteins were separated by sodium dodecyl sulfate polyacrylamide gel electrophoresis (SDS-PAGE) and transferred onto polyvinylidene fluoride (PVDF, Millipore, Bedford, MA) membranes. The PVDF membranes were first blocked with $5 \%$ bull serum albumin (BSA) for $1 \mathrm{~h}$ at room temperature, then incubated with the primary antibody [dilution for GAPDH was 1: 8000, Sigma, St. Louis, MO; dilutions for Bax/Bcl-2, caspase-1, COX2, iNOS, JNK, ERK 1/2 and p-p38 (Tyr182) were 1: 1000, Cell Signalling Technology, Beverly, MA] at $4^{\circ} \mathrm{C}$ overnight. On the next day, the PVDF membranes were washed 3 times for 10 min each time with Tris-buffered saline Tween (TBST), then incubated with horseradish peroxidase (HRP)-conjugated secondary 
A
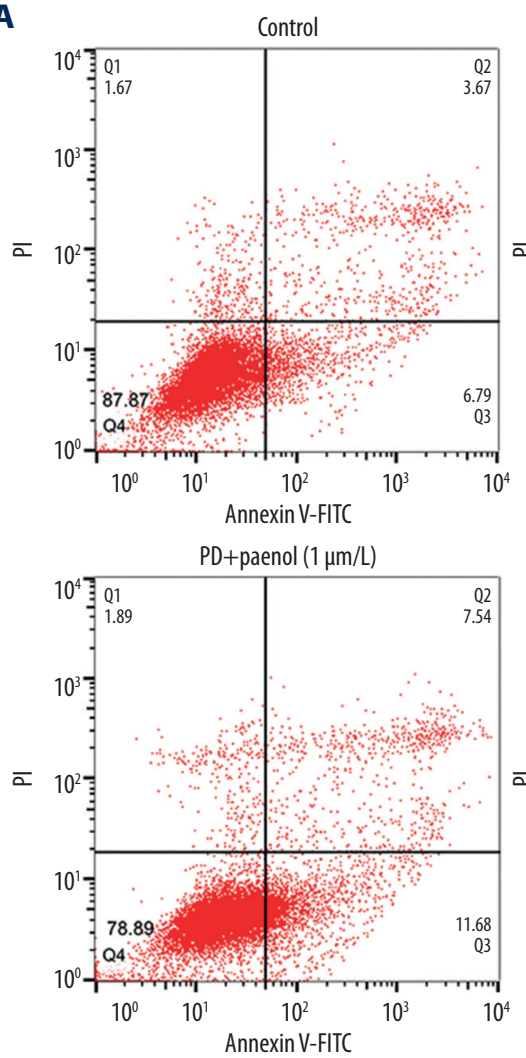

PD

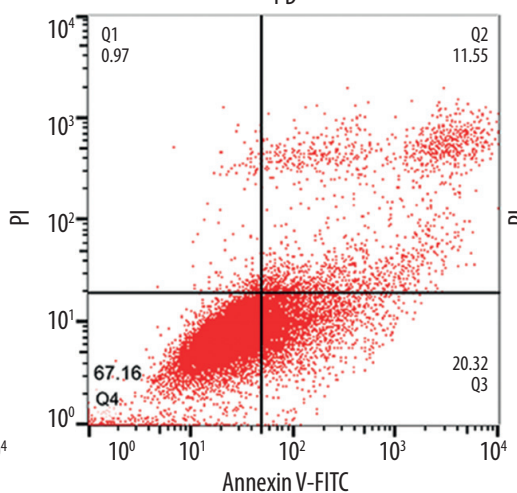

Annexin V-FITC

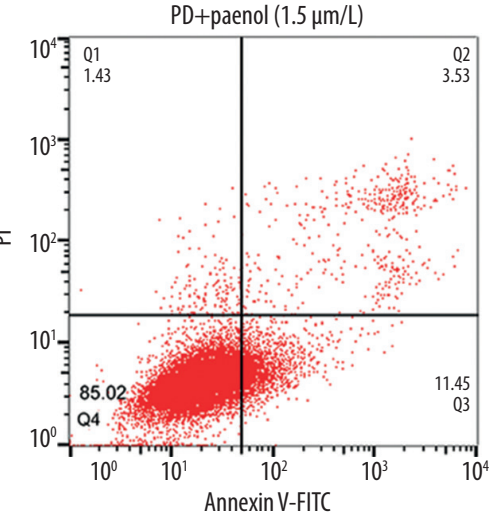

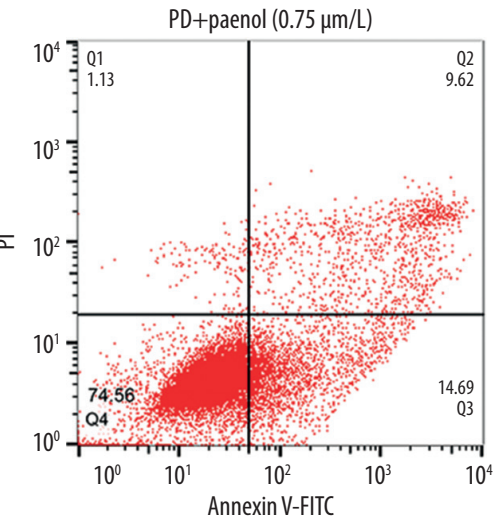

Annexin V-FITC

B

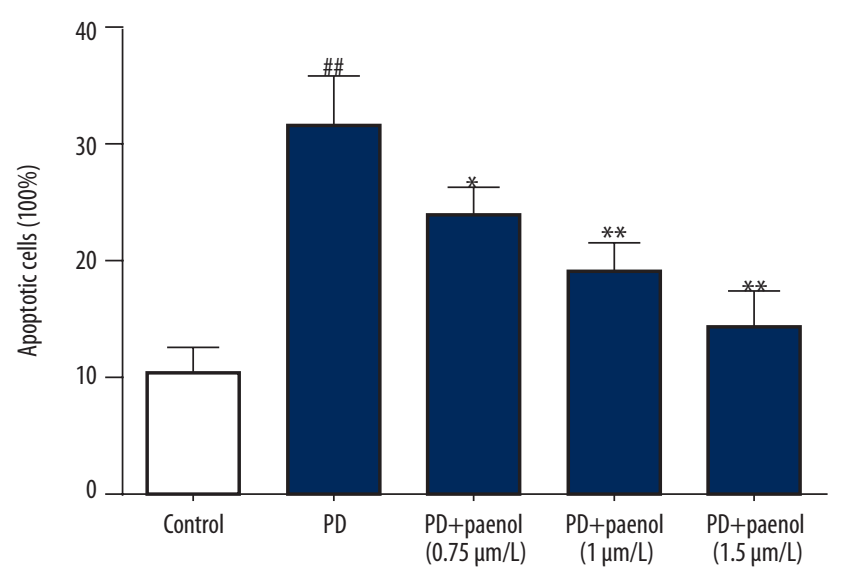

Figure 1. Paeonol inhibits MPP+-induced cell apoptosis of astrocytes. Compared with the control group, MPP+ obviously increased cell apoptosis of astrocytes, which was dose-dependently inhibited by paeonol $(0.75,1,1.5 \mu \mathrm{mol} / \mathrm{L})(\mathbf{A})$. The statistical data are also exhibited (B). ${ }^{\# \#} \mathrm{p}<0.01$ indicates there was a significant difference between the control group and PD group, * $\mathrm{p}<0.05$ or ** $p<0.01$ indicates there was a significant difference between the PD group and PD+Paeonol groups.

antibody for $1 \mathrm{~h}$ at room temperature. After washing 3 times with TBST, bands were developed with an ECL luminescence reagent. Glyceraldehyde-phosphate dehydrogenase (GAPDH) was the loading control.

\section{Cell viability}

Cell viability was evaluated by use of the MTT kit (Amresco, $\mathrm{OH})$ according to the manufacture's protocol. Briefly, $200 \mu \mathrm{l}$ 


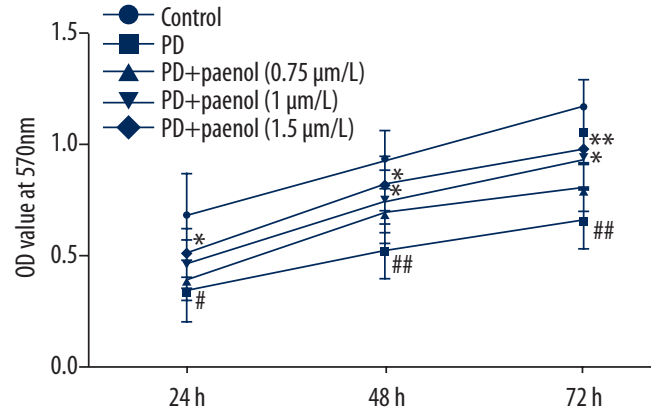

Figure 2. Paeonol rescues MPP+-induced down-regulation of cell viability in astrocytes. Compared with the control group, cell viability of astrocytes treated with MPP+ was seriously decreased, which was obviously and dose-dependently rescued by paeonol $(0.75,1,1.5$ $\mu \mathrm{mol} / \mathrm{L})$. \# $\mathrm{p}<0.05$ or $\# \#$ $p<0.01$ indicates there was a significant difference between the control group and PD group, ${ }^{*} p<0.05$ or ${ }^{* *} p<0.01$ indicates there was a significant difference between the PD group and PD+Paeonol groups.

$(1 \times 104 / \mathrm{ml})$ cells were seeded into $96-$ well plates and cultured for 24,48 , or $72 \mathrm{~h}$. After the addition of $20 \mu \mathrm{l}(5 \mathrm{mg} / \mathrm{ml})$ MTT into each well, cells were cultured for another $4 \mathrm{~h}$ at $37^{\circ} \mathrm{C}$ in an incubator. The culture medium was aspirated and the wells were washed with PBS and dried. Finally, $150 \mu \mathrm{DMSO}$ was added into each well. The dye was dissolved thoroughly by shaking. Absorbance at $570 \mathrm{~nm}$ was read by a BioRad iMark plate reader.

\section{Cell apoptosis}

We used an FITC apoptosis detection kit (Oncogene Research Products, San Diego, CA) to examine cell apoptosis, according to the manufacturer's protocol. Samples were first labeled with $\mathrm{PI}$ and V-FITC and then analyzed by flow cytometry (Becton Dickinson FACSVantage SE, San Jose, CA). The cells were divided into 4 group: early apoptotic cells were annexin V-FITCpositive and PI negative and late apoptotic cells were positive for both annexin V-FITC and PI. Cells that stained with neither annexin V-FITC nor PI were live cells.

\section{Statistical analysis}

Differences among groups were tested with one-way ANOVA followed by Bonferroni post hoc tests. $\mathrm{P}<0.05$ was considered as a significant difference.

\section{Results}

\section{Paeonol pretreatment reversed cell apoptosis induced by MPP+ in astrocytes}

To study the effect of paeonol treatment on protection of astrocytes, we measured cell apoptosis in different groups using FACS. We found that, compared with the apoptotic rate $(10.46 \%)$ in the control group, MPP+ obviously increased cell apoptosis of astrocytes ( $31.87 \%, p<0.01)$, which was dosedependently inhibited by paeonol $(24.31 \%$ for $0.75 \mu \mathrm{mol} / \mathrm{L}$, $\mathrm{p}<0.05 ; 19.22 \%$ for $1 \mu \mathrm{mol} / \mathrm{L}, \mathrm{p}<0.01 ; 14.98 \%$ for $1.5 \mu \mathrm{mol} / \mathrm{L}$, $\mathrm{p}<0.01$ ) (Figure 1A, 1B).
A

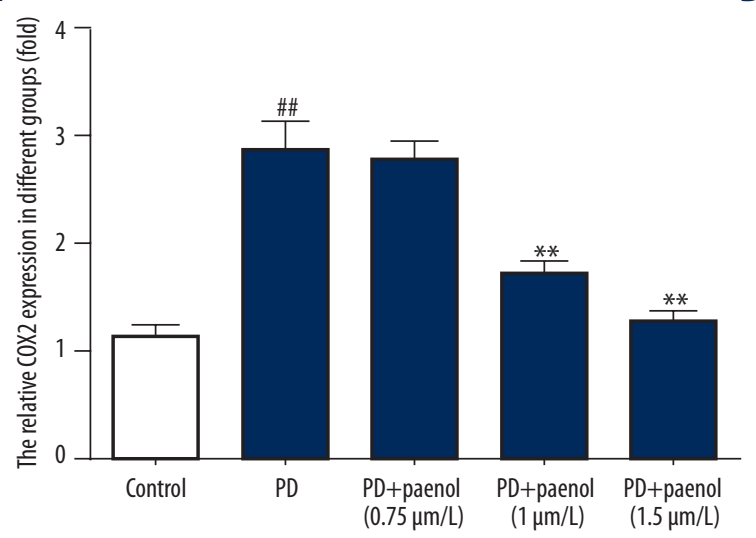

B

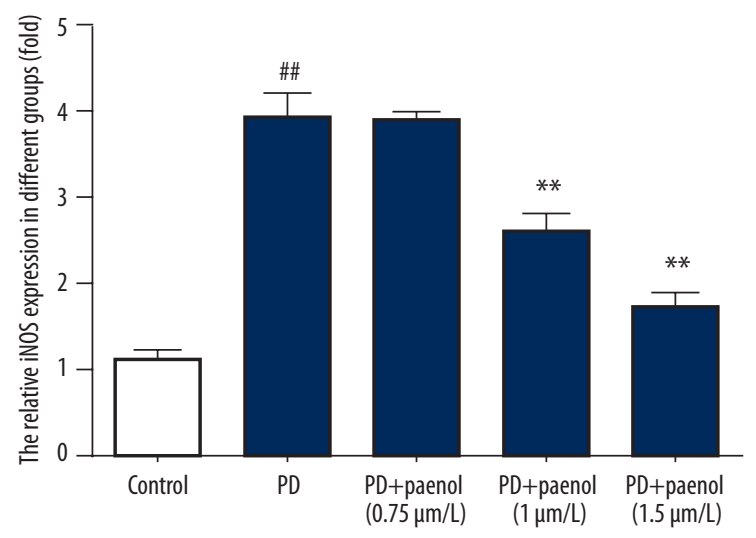

Figure 3. Paeonol inhibits MPP+-induced increase of COX2 and iNOS protein level in culture medium. There were higher COX2 (A) and iNOS (B) levels in the MPP+ group compared with the control group, which was lowered by paeonol $(0.75,1,1.5 \mu \mathrm{mol} / \mathrm{L})$. \#\# $p<0.01$ indicates there was a significant difference between the control group and PD group, ${ }^{* *} p<0.01$ indicates there was a significant difference between the PD group and PD+Paeonol groups. 


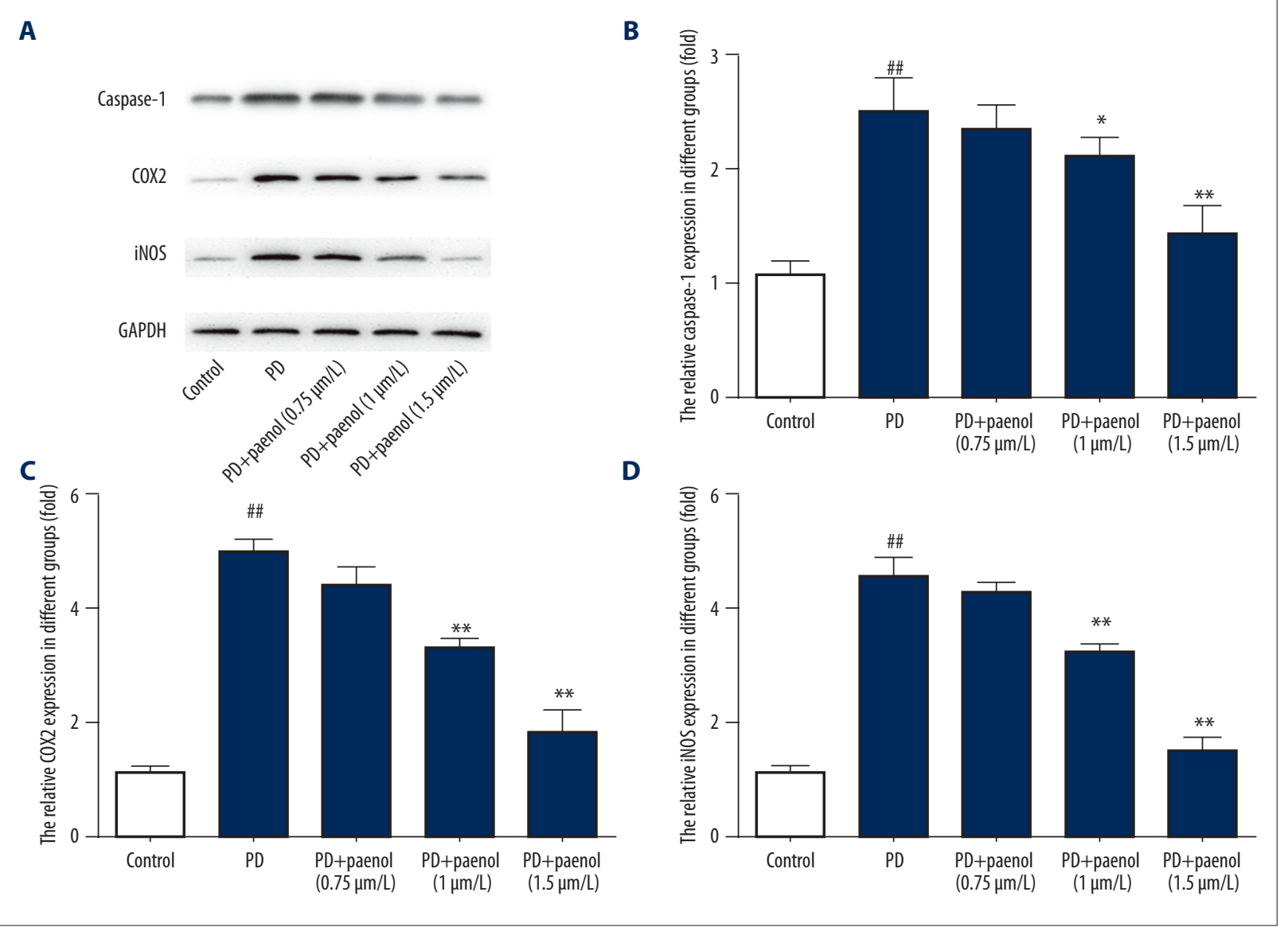

Figure 4. Paeonol inhibits MPP+-induced increase of caspase-1, COX2, and iNOS at protein level in astrocytes. Compared with the control group, there were higher protein levels of caspase-1 (A, B), COX2 (A, C), and iNOS (A, D) in astrocytes treated by $\mathrm{MPP}+$, which were repressed by paeonol $(0.75,1,1.5 \mu \mathrm{mol} / \mathrm{L})$. ${ }^{\# \#} \mathrm{p}<0.01$ indicates there was a significant difference between the control group and PD group, ${ }^{*} p<0.05$ or ${ }^{* *} p<0.01$ indicates there was a significant difference between the PD group and $\mathrm{PD}+$ Paeonol groups.

\section{Paeonol pretreatment reversed cell viability inhibition in astrocytes treated with MPP+}

Cell viability in different groups was evaluated by MTT assay. We discovered that compared with the control group, cell viability of astrocytes was greatly decreased by MPP+, which was obviously rescued by paeonol $(0.75,1,1.5 \mu \mathrm{mol} / \mathrm{L})$ dosedependently (Figure 2).

\section{Paeonol pretreatment reversed MPP+-induced COX2 and iNOS in culture medium}

COX2 and iNOS levels in the supernatant medium of cultured astrocytes were assessed by ELISA. Results demonstrated that there was higher COX2 level (near 3-fold, $p<0.01$ ) in the MPP+ group compared with the control group, which were lowered by paeonol (nearly 3-fold for $0.75 \mu \mathrm{mol} / \mathrm{L}, \mathrm{p}>0.05$; nearly 2 -fold for $1 \mu \mathrm{mol} / \mathrm{L}, \mathrm{p}<0.01$; and nearly the control level for $1.5 \mu \mathrm{mol} / \mathrm{L}$, $\mathrm{p}<0.01$ ), in a dose-dependent manner (Figure 3A).
Regarding the iNOS level, there was also significantly higher iNOS level (near 4-fold, $p<0.01$ ) in the MPP+ group compared with the control group, which were lowered by paeonol (nearly 4 -fold for $0.75 \mu \mathrm{mol} / \mathrm{L}, \mathrm{p}>0.05$; nearly 3 -fold for $1 \mu \mathrm{mol} / \mathrm{L}$, $\mathrm{p}<0.01$; and nearly 2 -fold for $1.5 \mu \mathrm{mol} / \mathrm{L}, \mathrm{p}<0.01$ ), in a dosedependent manner (Figure 3B).

\section{Paeonol pretreatment repressed caspase-1, COX2, and iNOS protein level induced by MPP+ administration in astrocytes}

Protein levels of casapse-1, COX2 and iNOS were examined by Western blot. Results showed that, compared with the control group, there were higher protein levels of caspase-1, COX2, and iNOS in astrocytes treated with MPP+, which were repressed by paeonol $(0.75,1,1.5 \mu \mathrm{mol} / \mathrm{L})$ (Figure $4 \mathrm{~A})$.

For casapse-1, there was a significantly higher casapse-1 level (nearly 2.5 -fold, $p<0.01$ ) in the MPP+ group compared with 


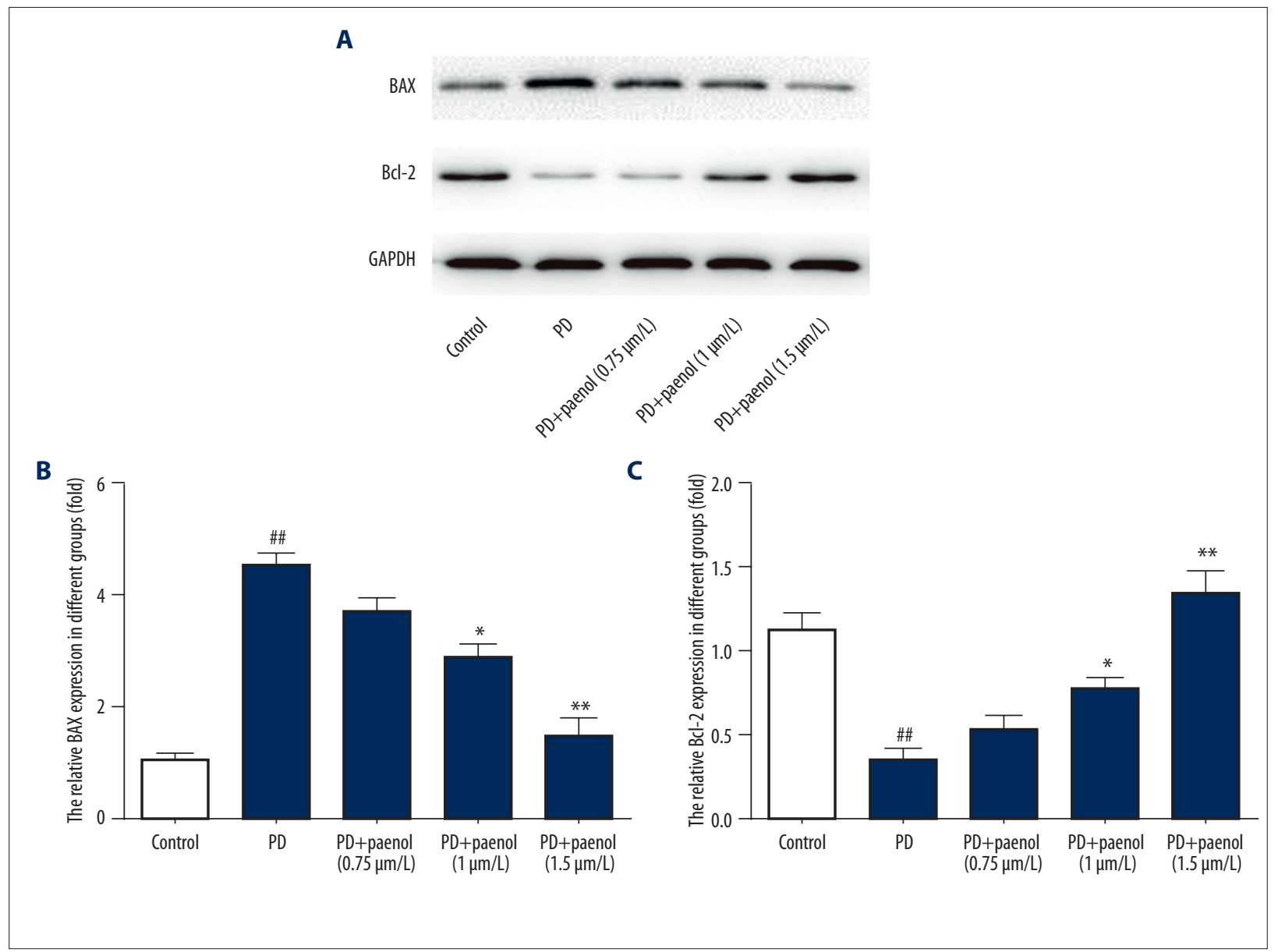

Figure 5. Paeonol inhibits MPP+-induced increase of Bax protein level and decrease of $\mathrm{Bcl}-2$ protein level in astrocytes. Compared with the control group, $\operatorname{Bax}(\mathbf{A}, \mathbf{B})$ protein level was increased while $\mathrm{Bcl}-2(\mathbf{A}, \mathbf{C})$ protein level was decreased after treatment of MPP+, which were all inhibited by paeonol $(0.75,1,1.5 \mu \mathrm{mol} / \mathrm{L})$. \#\# $\mathrm{p}<0.01$ indicates there was a significant difference between the control group and PD group, * $p<0.05$ or ${ }^{* *} p<0.01$ indicates there was a significant difference between the PD group and PD+Paeonol groups.

the control group, which were lowered by paeonol (nearly 2.5fold for $0.75 \mu \mathrm{mol} / \mathrm{L}, \mathrm{p}>0.05$; nearly 2 -fold for $1 \mu \mathrm{mol} / \mathrm{L}, \mathrm{p}<0.05$; and nearly normal level for $1.5 \mu \mathrm{mol} / \mathrm{L}, \mathrm{p}<0.01)$, in a dose-dependent manner (Figure 4B). Changes in profiles of COX2 and iNOS were similar to those of casapse-1 (Figure 4C, 4D).

\section{Paeonol pretreatment reversed Bax and Bcl-2 protein level altered by MPP+ administration in astrocytes}

Western blot analysis was used to assess protein levels of Bax and $\mathrm{Bcl}-2$ in astrocytes. Compared with the control group, Bax protein level was increased (by about 4-fold, $p<0.01$ ), while $\mathrm{Bcl}-2$ protein level was decreased (by about $33 \%, \mathrm{p}<0.01$ ) after treatment with $\mathrm{MPP}+$, and these changes were reversed by paeonol $(0.75 \mu \mathrm{mol} / \mathrm{L}, \mathrm{p}>0.05 ; 1 \mu \mathrm{mol} / \mathrm{L}, \mathrm{p}<0.05 ; 1.5 \mu \mathrm{mol} / \mathrm{L}$, $\mathrm{p}<0.01$ ) (Figure $5 \mathrm{~A}-5 \mathrm{C}$ ).

\section{Paeonol pretreatment repressed expression level of p-JNK/ p-ERK induced by MPP+ administration in astrocytes}

Protein levels of p-JNK/p-ERK/p-P38 in different groups were evaluated by Western blot. Results showed that in the MPP+ groups, all these protein levels were higher than those in the control group. Paeonol $(0.75,1,1.5 \mu \mathrm{mol} / \mathrm{L})$ inhibited increase of $p$-JNK $(p<0.01)$ and $p$-ERK $(p<0.01)$ but not $p-P 38(p>0.05)$, in a dose-dependent manner (Figure 6A-6D).

\section{Discussion}

We found that astrocytes that were pretreated with paeonol significantly rescued MPP+-induced cell viability reduction, and inhibited up-regulation of cell apoptosis, caspase- 1 activity, COX2, iNOS, and $\mathrm{Bax} / \mathrm{Bcl}-2$ ratio, as well as $\mathrm{p}-\mathrm{JNK}$ and 


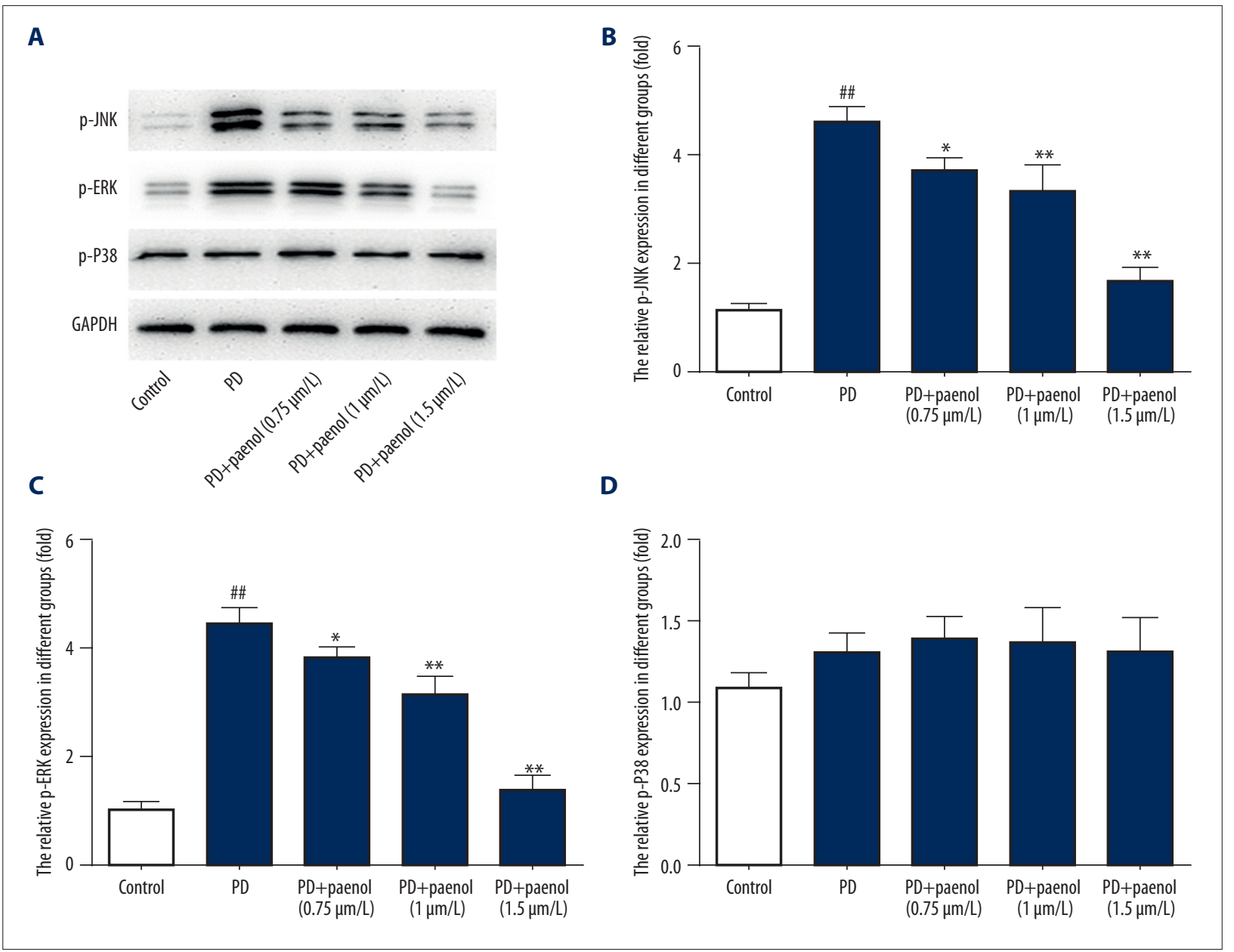

Figure 6. Paeonol inhibits MPP+-induced activation of $p$-JNK and $p$-ERK in astrocytes. In MPP+ groups, all protein levels were higher than those in the control group. Paeonol $(0.75,1,1.5 \mu \mathrm{mol} / \mathrm{L})$ inhibited increase of $\mathrm{p}$-JNK $(\mathbf{A}, \mathbf{B})$ and $\mathrm{p}$-ERK $(\mathbf{A}, \mathbf{C})$ in a dosedependent manner, but not p-P38 (A, D). \#\# p<0.01 indicates there was a significant difference between the control group and PD group, ${ }^{*} p<0.05$ or ${ }^{* *} p<0.01$ indicates there was a significant difference between the PD group and PD+Paeonol groups.

p-ERK. These findings suggest that paeonol is a neuroprotective agent suitable for use in the therapy of PD.

PD results from dopaminergic cell death [10], but the causes of the cell death are poorly understood [8]. Reactive astrocytosis in the SN demonstrated the correlation of astrocytes and inflammation in PD [15].

Paeonol has been reported to improve rat behavior in a model of Alzheimer's disease [19], reduce microglia activation in ischemia-reperfusion-injured rats [20], and to have anti-inflammatory action [21]. However, whether and how paeonol could be an effective drug for PD was unknown. The present study investigated the effects of paeonol in PD and explored a possible mechanism for the treatment of PD.
We first tested the cell apoptosis in astrocytes treated with or without paeonol before MPP+ administration. FCM results showed that there was an obviously higher astrocyte cell apoptosis rate in MPP+ treatment group than in control group, which was significantly restrained by the pretreatment with paeonol $(0.75,1,1.5 \mu \mathrm{mol} / \mathrm{L})$, and the effects of paeonol were dose-dependent. We also tested the cell viability of astrocytes in different groups; MTT results showed that there was lower astrocyte cell viability in the MPP+ treatment group than in the control group, which was dose-dependently rescued by the pretreatment of paeonol $(0.75,1,1.5 \mu \mathrm{mol} / \mathrm{L})$. These 2 results verified that paeonol indeed had a protective role in the MPP+induced astrocyte cell model of PD. However, the molecular mechanism underlying these observed cell behaviors is unclear.

Cyclooxygenase-2 (COX-2), which was first discovered by the Daniel Simmons laboratory in 1991 [22], was unexpressed in 
normal conditions but over-expressed in the process of inflammation. Inducible nitric oxide synthases (iNOS) was coded by the gene located on chromosome 17 [23]. Normally, there was a basal iNOS expression, while IRF1 and NF-kB-dependent activation of its promoter supported an inflammation-mediated stimulation of iNOS transcript [24]. Therefore, in the present study, we detected COX2 and iNOS levels in the supernatant medium and astrocytes by ELISA and Western blot, respectively. Results showed that there were higher COX2 and iNOS levels in the MPP+ group than in the control group, both of which were lowered by paeonol $(0.75,1,1.5 \mu \mathrm{mol} / \mathrm{L})$. These 2 results suggest the anti-inflammation activity of paeonol in the MPP+-induced PD model.

As MPP+ induced astrocyte cell apoptosis, we were eager to know the effects of paeonol on the related proteins (e.g., Bax and $\mathrm{Bcl}-2$ ). $\mathrm{Bcl}-2$ regulates cell death (apoptosis) [25] and the BAX gene has a pro-apoptotic role [26]. We detected the expression level of $\mathrm{BCl}-2$ and $\mathrm{Bax}$ by Western blot and found that, compared with the control group, the Bax protein level was increased and the $\mathrm{Bcl}-2$ protein level was decreased after treatment with MPP+, which were all inhibited by paeonol. These result reveal that paeonol plays a protective role in astrocytes via inhibiting cell apoptosis induced by MPP+.

We next continued to explore the up-stream molecules that might affect the aforementioned factors. MAPKAP kinase 2-deficiency was reported to prevent neuron death by inhibiting

\section{References:}

1. Parkinson J: An Essay on the Shaking Palsy. 1817. J Neuropsychiatry Clin Neurosci, 2002; 14(2): 223-36; discussion 222

2. Shulman JM, De Jager PL, Feany MB: Parkinson's disease: Genetics and pathogenesis. Ann Rev Pathol, 2011; 6: 193-222

3. de Lau LM, Breteler MM: Epidemiology of Parkinson's disease. Lancet Neurol, 2006; 5: 525-35

4. Noyce AJ, Bestwick JP, Silveira-Moriyama L et al: Meta-analysis of early nonmotor features and risk factors for Parkinson disease. Ann Neurol, 2012; 72: 893-901

5. Van Maele-Fabry G, Hoet P, Vilain F, Lison D: Occupational exposure to pesticides and Parkinson's disease: A systematic review and meta-analysis of cohort studies. Environ Int, 2012; 46: 30-43

6. Parkinson's Disease Information Page. NINDS. 2016

7. Jones HR: The Netter collection of medical illustrations. A compilation of paintings ( $2^{\text {nd }}$ ed.). Philadelphia, 2013; 161

8. Kalia LV, Lang AE: Parkinson's disease. Lancet, 2015; 386: 896-912

9. Jankovic J: Parkinson's disease: Clinical features and diagnosis. J Neurol Neurosur Psychiatry, 2008; 79: 368-76

10. Davie CA: A review of Parkinson's disease. Br Med Bull, 2008; 86: 109-27

11. Langston JW, Ballard P, Tetrud JW et al: Chronic Parkinsonism in humans due to a product of meperidine-analog synthesis. Science, 1983; 219: 979-80

12. Marongiu ME, Piccardi MP, Bernardi F et al: Evaluation of the tox icity of the dopaminergic neurotoxins MPTP and MPP+ in PC12 pheochromocytoma cells: Binding and biological studies. Neurosci Lett, 1988; 94 349-54

13. McGeer PL, Schwab C, Parent A et al: Presence of reactive microglia in monkey substantia nigra years after 1-methyl-4-phenyl-1,2,3,4-tetrahydropyridine administration. Ann Neurol, 2003; 54: 599-604 neuroinflammation in a mouse model of PD [27], and JNK was recently reported to be correlated with $\mathrm{PD}$ with the regulation of miRNA-181a [28]. Consequently, we examined the protein levels of p-JNK/p-ERK/p-P38 in different groups. Results showed that in MPP+ groups, all protein levels were higher than in the control group, and paeonol pretreatment inhibited increase of $\mathrm{p}$-JNK and p-ERK in a dose-dependent manner, but not p-P38.

Thus, taken together, our work suggests that paeonol targets $\mathrm{p}-J N K / p-E R K$ to regulate key proteins involved in inflammation and cell apoptosis, thereby protecting astrocytes from MPP+-induced PD.

\section{Conclusions}

The present study found that paeonol protects cells from apoptosis and inflammation by repressing the activation of the JNK/ ERK-related signalling pathway, which was induced by MPP+ in astrocytes. Our study shows that paeonol may be a neuroprotective agent for the treatment of PD patients, with great promise in the future. Paeonol may also be used for treatment of other inflammation-related diseases.

\section{Conflicts of interest}

None.

14. Barcia C, Sanchez Bahillo A, Fernandez-Villalba E et al: Evidence of active microglia in substantia nigra pars compacta of parkinsonian monkeys 2 year after MPTP exposure. Glia, 2004; 46: 402-9

15. Mirza B, Hadberg $\mathrm{H}$, Thomsen $\mathrm{P}$ et al: The absence of reactive astrocytosis is indicative of a unique inflammatory process in Parkinson's disease. Neurosci, 2000; 95: 425-32

16. Fukuhara Y, Yoshida D: Paeonol: A bio-antimutagen isolated from a crude drug, moutan cortex. Agric Biol Chem, 1987; 51: 1441-42

17. Wu XN, Chen HL, Chen XG et al: Determination of paeonol in rat plasma by high-performance liquid chromatography and its application to pharmacokinetic studies following oral administration of Moutan cortex decoction. Biomed Chromatogr, 2003; 17: 504-8

18. Deng $\mathrm{CH}$, Yao N, Wang B et al: Development of microwave-assisted extraction followed by headspace single-drop microextraction for fast determination of paeonol in traditional Chinese medicines. J Chromatogr A, 2006; 1103: 15-21

19. Zhou J, Zhou L, Hou DR et al: Paeonol increases levels of cortical cy tochrome oxidase and vascular actin and improves behavior in a rat model of Alzheimer's disease. Brain Res, 2011; 1388: 141-47

20. Hsieh CL, Cheng, CY, Tsai TH et al: Paeonol reduced cerebral infarction involving the superoxide anion and microglia activation in ischemia-reperfusion injured rats. J Ethnopharmacol, 2006; 106: 208-5

21. Chou TC: Anti-inflammatory and analgesic effects of paeonol in carrageenan-evoked thermal hyperalgesia. Brit J Pharmacol, 2003; 139: 1146-52

22. Xie WL, Chipman JG, Robertson DL et al: Expression of a mitogen-responsive gene encoding prostaglandin synthase is regulated by mRNA splicing. Proc Natl Acad Sci USA, 1991; 88: 2692-96

23. Knowles RG, Moncada S: Nitric oxide synthases in mammals. Biochem J, 1994; 298: 249-58 
24. Green SJ, Scheller LF, Marletta MA et al: Nitric oxide: cytokine-regulation of nitric oxide in host resistance to intracellular pathogens. Immunol Lett, 1994; 43: 87-94

25. Cleary ML, Smith SD, Sklar J: Cloning and structural analysis of cDNAs for bcl-2 and a hybrid bcl-2/immunoglobulin transcript resulting from the $(14 ; 18)$ translocation. Cell, 1986; 47: 19-28

26. Oltvai ZN, Milliman $\mathrm{CL}$, Korsmeyer SJ: $\mathrm{Bcl}-2$ heterodimerizes in vivo with a conserved homolog, Bax, that accelerates programmed cell death. Cell, 1993; 74: 609-19
27. Thomas $T$, Timmer $M$, Cesnulevicius $K$ et al: MAPKAP kinase 2-deficiency prevents neurons from cell death by reducing neuroinflammation-relevance in a mouse model of Parkinson's disease. J Neurochem, 2008; 105: 2039-52

28. Liu $Y$, Song $Y$, Zhu X: MicroRNA-181a regulates apoptosis and autophagy process in Parkinson's disease by inhibiting p38 Mitogen-Activated Protein Kinase (MAPK)/c-Jun N-Terminal Kinases (JNK) signaling pathways. Med Sci Monit, 2017; 23: 1597-606 